Tarbawy : Jurnal Pendidikan Islam

ISSN : 2407-4462 (Cetak), 2614-5812 (Elektronik)

Vol. 7, No.1, 2020, Hal. 1-5

DOI: https://doi.org/10.32923/tarbawy.v7i1.1188

\title{
Implementasi Sistem Manajemen Mutu Iso 9001:2008 Di MAN 3 Sleman (Upaya Peningkatan Mutu Guru Mata Pelajaran PAI)
}

\author{
Muhammad Rofiq Anwar ${ }^{1}$ \\ ${ }^{1}$ IAIN Syaikh Abdurrahman Siddik Bangka Belitung
}

\section{Info Artikel :}

Diterima 4 April 2020

Direvisi 22 April 2020

Dipublikasikan 27 April 2020

\section{Kata Kunci:}

Implementasi

Manajemen Mutu ISO

MAN 3 Sleman

Keywords:

Implements

Quality Management System

MAN 3 Sleman

\section{Koresponden:}

\begin{abstract}
ABSTRAK
Peneliti ini memfokuskan pada Impelementasi Sistem Manajemen Mutu ISO 9001:2008 di MAN 3 Sleman dalam Upaya Peningkatan Mutu Guru Mata Pelajaran PAI. Jenis penelitian ini menggunakan penelitian lapangan (field reseach) yang bersifat kualitatif dengan mengambil latar MAN 3 Sleman. Pendekatan yang digunakan adalah kualitatif. Subyek penelitian ini adalah kepala madrasah, wakil kepala madrasah MAN 3 Sleman, guru Man 3 Sleman, guru BK, dan siswa MAN 3 Sleman sedangkan obyek penelitiannya berkaitan dengan Implementasi Sistem Manajemen Mutu ISO 9001:2008 di Man 3 Sleman (Upaya Peningkatan Mutu Guru PAI).. Hasil penelitian menunjukkan bahwa Implementasi Sistem Manajemen Mutu ISO 9001:2008 sangat tepat dalam Upaya peningkatan Mutu Guru Mata Pelajaran PAI. Impelementasi sistem manajemen mutu ISO 9001:2008 sudah dilakukan dengan sangat baik. Dalam upaya peningkatan mutu guru mapel PAI melalui sistem manajemen mutu ISO 9001:2008, MAN 3 Sleman melalui peningkatan kompetensi pedagogik dan kompetensi profesionalisme. Terdapat faktor kelebihan dan kekurangan dalam melaksanakan implementasi sistem manajemen mutu ISO 9001:2008 (upaya peningkatan mutu guru PAI di MAN 3 Sleman). Kelebihannya yaitu adanya keteraturan dan ketertiban diberbagai lini karena sesuai standar sasaran mutu. Sedangkan kekurangannya adalah masih ada beberapa guru PAI yang kurang sadar akan pentingan penerapan sistem manajemen tersebut.
\end{abstract}

\section{ABSTRACT}

this research focus on advanced of education depends on the management system /management in an educational institution, especially religious-based educational institutions such as MAN 3 Sleman. This research is a field research (field reseach) that is qualitative, by taking the background MAN 3 Sleman. The approach used a qualitative. The subjects of this research are head of madrasah, deputy head of madrasah MAN 3 Sleman, teacher of 3 Sleman, BK teacher, and student of MAN 3 Sleman while the object of research is related to Implementation of Quality Management System ISO 9001: 2008 in Man 3 Sleman (Improvement Effort of PAI Teacher Quality). Data collection is done by conducting observation, interview and documentation. The results show that the Implementation of ISO 9001: 2008 Quality Management System is very appropriate in Improving Quality Teachers of PAI Subject Teachers. Impelementasi quality management system ISO 9001: 2008 has been done well. In an effort to improve the quality of PAI mapel teachers through ISO 9001: 2008 quality management system, Man 3 Sleman through the path of pedagogic competence improvement and professionalism competence. There are advantages and disadvantages in implementing the system quality management of ISO 9001 : 2008 in an effort to improve the quality of PAI teachers in MAN 3 Sleman. The excess is the existence of order and order in various lines because according to the standard of quality objectives. While the drawback is there are still some PAI teachers who are less aware of the importance of the implementation of the management system. 


\section{Pendahuluan}

Dewasa ini, perkembangan IPTEK membawa pengaruh terhadap perkembangan pendidikan. Negara yang maju bisa diukur dari kemajuannya dan penguasaan terhadap teknologi informasi. Dunia pendidikan saat ini diguncang oleh berbagai perubahan sesuai dengan tuntutan dan kebutuhan masyarakat. Perubahan dan permasalahan lokal maupun perubahan global yang terjadi begitu pesat. Perubahan dan permasalahan tersebut menurut Prof. Sanusi mencakup social change, turbulence, complexity, and chaos, seperti pasar bebas (free trade), tenaga kerja bebas (free labour), perkembangan masyarakat informasi, serta perkembangan ilmu pengetahuan, teknologi, seni, dan budaya yang sangat dasyat(Mulyasa \& Mukhlis, 2007). Disamping hal tersebut, realita yang terjadi di Indonesia ini sumber daya manusia masih dinilai rendah, dan daya saing dalam dunia kerja luar negerijuga rendah. Hal ini dibuktikan dengan jumlah ekspor Indonesia masih kalah dengan Negara-negara tetangga seperti Malaysia, Singapore, dan sebagainya(Joko widodo, 2018).

Oleh karena itu, maka perlu adanya kemampuan dalam meningkatkan efektifitas pada proses sistem manajemen mutu, sehingga mampu memberikan hasil yang maksimal sesuai dengan tujuan dan sasaran mutu yang telah ditetapkan, dan perlu adanya suatu progam berkesinambungan yg perlu didukung oleh semua personel yang terlibat dalam penerapan sistem ini.Sedangkan yang berkaitan dengan mutu kelulusan (output) sekolah, dapat dijelaskan bahwa output sekolah bisa dikatakan tinggi, jika prestasi sekolah, kususnya prestasi belajar siswa, menunjukan capaian tinggi dalam (1) prestasi akademik, berupa nilai UAS, UN, karya ilmiah dan lomba-lomba akademik, (2) prestasi non akademik seperti misalnya, olahraga, ketrampilan, dan kegiatan ekstrakulikuler lainnya, (3) tingkat diserapnya lulusan oleh dunia usaha dan dunia industri dengan persentase tinggi. Mutu sekolah dipengaruhi oleh banyak tahapan kegiatan yang saling berhubungan (proses) seperti misalnya perencanaan, pelaksanaan dan pengawasan(Anne Sukmawati, 2014). Termasuk di dalamnya adalah yang paling terpenting KBM disekolah.

Produk dalam suatu perusahaan adalah berupa barang. Sedangkan produk dari suatu lembaga atau instansi seperti sekolah adalah KBM. Karena dengan KBM bagus akan dihasilkan kepuasan pelanggan baik internal maupun eksternal(Saraswati, 2016).Untuk mewujudkan tujuan pendidikan yang berkualitas, maka MAN 3 Sleman secara gigih menerapkan konsep manajemen mutu, yaitu dengan menerapkan ISO 9001:2008. Dalam keunggulannya output yang dihasilkan dapat diterima di beberapa PTN ternama di indonesia. Bukti kesungguhan dan kekompakan semua civitas akademik yang ada di MAN 3 Sleman adalah diterapkannya manajemen mutu pada tanggal 02 Juni 2014 memperoleh sertifikat ISO 9001 : 2008.Melalui manajemen ISO 9001 : 2008 MAN 3 Sleman berupaya meningkatkan kualitas produk yaitu KBM sekolah melalui peningkatan mutu Guru, salah satunya adalah guru mata pelajaran PAI agar output madrasah yg berupa lulusan tidak hanya diterima di PTN ternama, seperti halnya yang di katakan oleh bapak Angga M.Pd.I selaku Guru BK bahwa " siswa MAN 3 Sleman pada tahun 2016 dengan jumlah 102 dari 190 siswa diterima di PTN ternama, dan sisanya diterima di PTS ternama(Angga, 2016). Disamping diterimanya di PTN ternama, lulusan MAN 3 Sleman juga berakhlakul karimah dan dapat bersaing di era global terutama dalam menghadapi globalisasi yang berkembang begitu pesat.

\section{Metode}

Bedasarkan bentuknya, penelitian ini menggunakan penelitian lapangan (field research). Penelitian ini menggunakan pendekatan kualitatif. Penelitian kualitatif dipandang cocok karena bersifat alamiah dan menghendaki keutuhannya. Dalam penelitian ini dapat diusahakan untuk mendeskripsikan permasalahan secara komprehensif, holistic, integrative, dan mendalam melalui kegiatan mengamati orang dalam lingkungannya dan berinteraksi dengan mereka tentang dunia sekitarnya(Nasution, 1996).

\section{Hasil dan Pembahasan}

\section{Implementasi Sistem Manajemen Mutu ISO 9001:2008}

Untuk menuju Madrasah yang bermutu, MAN 3 Sleman mengadopsi dedikasi bersama terhadap mutu oleh segenap dewan sekolah, guru, siswa, administratif, staf, dan komunitas. Prosesnya diawali dengan mengembangkan visi dan misi mutu, visi mutu tersebut difokuskan untuk pemenuhan kebutuhan kostumer, mendorong keterlibatan total komunitas dalam progam, mengembangkan sistem pengukuran nilai tambah pendidikan, menunjang sistem juga diperlukan siswa dan staf untuk mengelola perubahan, serta perbaikan berkelanjutan dengan selalu berupaya keras membuat produk pendidikan yang lebih baik. 
Dalam pelaksanaan Sistem manajemen ISO 9001:2008, maka MAN 3 Sleman memiliki langkahlangkah sebagai berikut:

a. Memutuskan dan mengadopsi suatu standar sistem manajemen kualitas yang diterapkan, standarstandar sistem manajemen kualitas itu dipilih berdasarkan sesuai dengan kebutuhan pelanggan.

b. Menetapkan suatu komitmen pada tingkat pemimpin senior dan organisasi (Top Manajement Comitment)

c. Menetapkan suatu kelompok kerja ( Team work)

d. Mengevaluasi sistem yang sudah berjalan sebelum diterapkannya sistem manajemen ISO 9001:2008

e. Menerapkan sistem manajemen mutu ISO 9001:2008 dengan menetapkan standar mutu diberbagai lini manajamen, dari ketatausahaan, kurikulum, kesiswaan, dll.

f. Melakukan evaluasi melalui audit internal dan eksternal.

g. Sertifikasi(Prabowo, 2009).

Penerapan atau pelaksanaan sistem manajemen mutu ISO 9001:2008 di MAN 3 Sleman dapat

ditinjau dari 5 Aspek, yaitu :

a) Komitmen Ketua dan Tim

Komitmen Top Manajemen beserta segenap tim sistem manajemen mutu ISO 9001:2008 di MAN 3 Sleman sangat diperlukan. Karena kedua faktor tersebut sangat diperlukan untuk mewujudkan visi dan misi diterapkannya sistem manajemen mutu ISO di MAN 3 Sleman, yaitu tercapainya target standar sasaran mutu diberbagai lini, yaitu di bidang kurikulum, kesiswaa, tata usaha, dll. Hal tersebut sesuai dengan apa yang dipaparkan bapak Prihantoro selaku ketua manajemen mutu ISO 9001:2008 di MAN 3 Sleman bahwa "kelebihan dari diterapkannya sistem manajmen mutu adalah tercapainya sasaran mutu disemuai lini manajmen, misalkan di bidang tata usaha, kesiswaan, dll(Prihantara, 2016)."Selain itu, komitmen TOP manajmen beserta tim memiliki komitmen berupa mengunggulkan prinsip-prinsip sistem manajemen mutu, membangkitkan secara bersama inovasi dan kreatifitas agar mencapai apa yang ada dalam visi dan misi diterapkannya sistem manajemen mutu ini.

b) Kurikulum Yang Sesuai Dengan Kebutuhan Pelanggan

Kurikulum adalah salah satu penentu yang menjadikan output suatu lembaga, atau dalam hal ini madrasah berkualitas atau mempunyai daya saing yang tinggi atau tidak. Kurikulum dari tahun ke tahun selalu sering berubah menyesuaikan dengan kebutuhan jaman. Maka dari itu, MAN 3 Sleman dalam hal ini menerapkan kurikulum 2013 yang orientasinya lebih mengajari dan mendidik anak untuk lebih bereksplorasi dan mandiri dalam belajar. Sesuai dengan salah satu tujuan sistem manajemen mutu yaitu memnuhi kebutuhan pelanggan. Sedangkan kurikulum yang dibutuhkan pelanggan saat ini adalah kurikulum 2013.

c) Guru atau Pengajar Yang Bermutu

Guru adalah penentu atau kunci dalam menciptakan lulusan yang berkualitas. Karena guru dalam hal ini mempunyai 3 tugas besar, yaitu :

1) Tugas profesi, yaitu mendidik dan menumbuh kembangkan kepribadian positif pada anak didik, mengajar atau mentranfer ilmu pengetahuan, dan melatih ketrampilan anak didik.

2) Tugas manusiawi, yaitu membantu siswa mengenai dirinya sendiri, selain itu guru adalah orang tua kedua dimadrasah.

3) Tugas Masyarakat yaitu, guru membantu anak didik untu menjadi warga masyarakat bahkan warna negara yang baik.

Oleh karena itu, maka dalam menerapkan sistem manajemen ISO 9001:2008, MAN 3 Sleman harus menyeleksi, memilih guru ysng benar-benar berkualitas, agar pelaksanaan implementasi sistem manajemen mutu ISO 9001:2008 berjalan dan sesuai dengan sasaran standar mutu yang diharapkan. sesuai dengan penyataan bapak Prihantoro selaku ketua sistem amanajemen mutu di MAN 3 Sleman, yaitu "Bahkan sebelum mengajar, guru harus di awasi dan di pantau tentang perangkat mengajarnya enam bulan atau untuk satu tahun kedepan. Sekiranya agar ketika mengajar guru benar-benar mengusai materi dan tidak lupa sampai mana dan apa yang harus disampaikan kepada anak didik"(Prihantara, 2016) .

d) Input Siswa yang baik

Dalam penerimaan siswa, MAN 3 Sleman mekakukan seleksi yang ketat dengan menggunakan standar nilai dan standar nilai rata-rata nilai akhir 7,8. Disamping itu, MAN 3 Sleman melakukan progam Penerimaan peserta didik baru (PPDB) dalam 3 tahap. Tahap 1 dan 2 adalah PPDB jalur prestasi. Dimana pada kedua jalur tersebut yang disaring dan diseleksi adalah siswa-siswa yang mempunyai nilai rapot yang bagus. Sehinggs ysng diterima pun siswa MTs atau setara SMP yang berkualitas dan berstandar tinggi, yang nantinya mampu mengikuti progam-progam unggulan MAN 3 Sleman.

e) Lulusan yang Mempunyai Daya Saing 
Output suatu lembaga yang menerapkan sistem manajemen mutu ISO 9001:2008 adalah salah satu dari hasil atau produk dari pada manajmenen mutu tersebut. Sehingga keberhasilan dari Madrasah MAN 3 Sleman yang sudah menerapkan sistem manajemen mutu tersebut mempunyai sasaran mutu output yang berkualitas dan berakhlakul karimah. Sehingga nantinya mampu bersaing dan masuk Perguruan Tinggi ternama maupun perguruan tinggi swasta yang berkualitas.

\section{Evaluasi}

MAN 3 Sleman melakukan evaluasi minimal satu tahun sekali, yaitu berupa audit internal sebelum dilakukan audit eksternal Oleh pihak perusahan yang diajak kerjasama, dalam hal ini perusahaan sistem manajemen mutu ISO 9001:2008. Dalam audit internal ini, pihak tim internal MAN 3 Sleman menunjuk beberapa personal atau anggota yang dianggap senior atau memiliki kompetensi sesuai bidangnya masingmasing. Misalkan dalam kesiswaan ditunjuk waka kesiswaan, dalam hal audit guru atau pengajar maka ditunjuk guru senior untuk mengaudit guru yang lebih yunior dalam ilmu dan pengalaman. Agar tercapai di masing-masing lini standar mutu yang diharapkan. sesuai dengan hasil wawancara dengan bapak prihantoro selaku ketua manajemen mutu yaitu "Evaluasi sangat diperlukan diberbagai lini agar terciptanya saran mutu yang diharapkan"(Prihantara, 2016).

Dengan demikian, maka implementasi manajemen mutu akan mencapai dengan target saran mutu sesuai dengtan visi dan misinya. Serta dengan bebberapa tahap tersebut maka MAN 3 Sleman akan mendapatkan sertifikat ISO 9001:2008 yaitu sistem manajemen yang berstandar internasional.

\section{Upaya Meningkatkan Mutu Guru Mapel PAI}

Guru atau pengajar, terutama guru mapel PAI sangatlah berpengaruh dalam perkembangan anak didik. Dengan latar belakang madrasah, maka sudah seharusnya lah guru mapel PAI MAN 3 Sleman memiliki dedikasi dan standar kualitas yang tinggi agar tercapainya salah satu produk sistem manajemen mutu ISO 9001:2008 yaitu KBM yang berkualitas karena dibawakan oleh guru yang berkompetensi dan berkualitas. Sebagaimana yang dituturkan oleh bu Hanawasti selaku Waka Sarpras dan Wakil ketua tim internal sistem manajemen mutu ISO 9001:2008 di Man 3 Sleman, yaitu "Salah satu produk sistem amanjemen ISO adalah jasa yang berupa KBM(Saraswati, 2016)". dan sesuai penuturan bapak Prihantoro selaku ketua adalah "Guru yang tidak siap dengan perangkat mengajar, baik itu RPP, silabus, Promes, atau Prota, maka guru tersebut tidak layak untuk mengajar, karena bisa jadi dia kurang menguasai materi dan sebagainya(Saraswati, 2016)."

Maka, dari pernyataan kedua orang tersebut yaitu bapak Prihantoro dan ibu Hanaswati sekalu ketua dan wakil yang mengurusi implementasi manajemen mutu ISO 9001:2008 bisa dijabarkan bahwa seorang guru apalagi guru PAI harus mempunyai rencana mengajar, dalam artian melengkapi semua hal yang berhubungan dengan administrasi atau perangkat mengajar dan penguasaan materi demi tercapai tercapainya sasaran mutu yang distandarkan dalam manajemen yang berbasis internasional tersebut.

Dalam Upaya meningkatkan kualitas guru mapel PAI, MAN 3 Sleman melalui penerapan sistem manajemen mutu ISO 9001:2008 dapat dilihat melalui 2 kompetensi guru, yaitu kompetensi pedagogik dan kompetensi profesional.

Pertama, dalam kompetensi pedagogik yang meliputi landasan pendidikan, yaitu mengembangan kurikulum, pembuatan RPP, silabus, Prosem, Prota. Dalam hal ini upaya peningkatan mutu guru agar tetap memenuhi standar kompetensi pedagogik ini, maka setiap awal tahun atau awal semester dilakukan pengecekan administratif dan kesiapan guru PAI sebelum mengajar oleh guru yang dianggap senior yang ditunjuk sekolah untuk selalu memonitor. Dan apabila ketika dimonitor guru PAI tersebut masih ada temuan dalam menyelesaikan perangkat mengajarnya, misalkan RPP belum seslesai dibuat, maka diberi tenggang waktu terntu untuk segera menyelesaikan perangkat yang kurang tersebut. Hal ini dinyatakan oleh bapak Prihantoro selaku ketua manajemen ISO di MAN 3 Sleman, yaitu "Setiap Awal Tahun dan awal semester dilakukan mengecekan atau monitoring oleh guru PAI yang dianggap senior kepeda guru yunior mengenai kelengkapan perangkat mengajar, contoh RPP, silabus dll. Jika ada temuan, maka guru tersebut diberi tenggang waktu tertentu untuk segera melengkapi perangkat mengajar tersebut(Prihantara, 2016)"

Dan untuk menunjang kompetensi pedagogik yang baik, maka Man 3 Sleman dalam menerima guru PAI baru melalui proses yang ketat, yaitu harus berstandar minimal berpendidikan Strata satu (S1) pendidikan Agama Islam atau bergelar S.Pd.I dan memiliki sertifikat akta empat. Kedua dalam penerapan profesionalisme guru yang meliputi dari aspek 1)sebagai pekerja profesional dengan fungsi mengajar, membimbing, melatih 2) Pekerja kemanusiaan dengan fungsi dapat merealisasikan seluruh kemampuan 
kemanusiaan yang dimiliki 3) Sebagai petugas kemaslahatan yang baik yang berfungsi mengajar danmendidik masyarakat agar menjadi warga negara yang baik(Latifah, 2000). Dari tigsa kompetensi tersebut MAN 3 Sleman selain memonitor dari segi pedagogik juga memonitor gerak-gerik guru PAI baik perannya disekolah maupun di masyarakat. karena perannya di kedua tempat tersebut yang nantinya akan mempengaruhi antar lain kesuksesan di bidang promosi dan komunikasi dengan masyarakat dan keduanya termasuk dari proses penerapan sistem manajemen mutu ISO 9001:2008.

\section{Kesimpulan}

Setelah mengkaji dan meneliti tentang implementasi sistem manajemen mutu ISO 9001:2008 di MAN 3 Sleman dalam upaya peningkatan mutu guru mapel PAI, maka penulis dapat menyimpulkan :

1. Impelemntasi sistem manajemen mutu ISO 9001:2008 sudah dilakukan dengan baik.

2. Dalam upaya peningkatan mutu guru mapel PAI melalui sistem manajemen mutu ISO 9001:2008, Man 3 Sleman melalui jalur peningkatan kompetensi pedagogik dan kompetensi profesionalisme.

Terdapat faktor kelebihan dan kekurangan dalam melaksanakan implementasi sistem manajemen mutu ISO 9001:2008 dalam upaya peningkatan mutu guru PAI di MAN 3 Sleman. Kelebihannya yaitu adanya keteraturan dan ketertiban diberbagai lini karena sesuai standar sasaran mutu. Sedangkan kekurangannya adalah Masih ada beberapa guru Pai yang kurang sadar akan pentingan penerapan sistem manajemen tersebut.

\section{Daftar Pustaka}

Angga. (2016). Wawancara. Sleman.

Anne Sukmawati. (2014). Aplikasi SMM 9001:2000 di SMKN 7 Bandung. Bandung.

Joko widodo. (2018). pidato presiden.

Latifah, L. (2000). Kompetensi Sosial, Status Sosial, Dan Viktimisasi Disekolah Dasar. Skripsi, Tidak Diterbitkan, Fakultas Psikologi Universitas Gajah Mada Yogyakarta.

Mulyasa, E., \& Mukhlis. (2007). Standar kompetensi dan sertifikasi guru. Remaja Rosdakarya.

Nasution, S. (1996). Metode Penelitian Naturalistik Kualitatif Tarsito. Bandung.

Neuman, W. L. (2017). Metodologi Penelitian Sosial: Pendekatan Kualitatif dan Kualitatif (Edisi Tujuh). Jakarta: PT. Indeks. Halaman, 44.

Prabowo, S. L. (2009). Implementasi sistem manajemen mutu ISO 9001: 2008 di perguruan tinggi (guidelines IWA-2). UINMaliki Press.

Prihantara. (2016). Wawancara. Sleman.

Saraswati, H. (2016). Wawancara. Sleman. 